\title{
Análise da variação da cobertura do solo no Pantanal de 2003 a 2010 através de sensoriamento remoto
}

\author{
Analysis of landcover changes using remote sensing between 2003 \\ and 2010 in the Pantanal region
}

\section{Antonio Conceição Paranhos Filho', Erika Silva Moreira², Ademir Kleber Morbeck de Oliveira³, Teresa Cristina Stocco Pagotto ${ }^{4}$, Camila Leonardo Mioto 5}

\begin{abstract}
RESUMO
O Pantanal é um dos ecossistemas mais ricos em biodiversidade do Brasil, estendendo-se pelos territórios de Mato Grosso e de Mato Grosso do Sul, além de pequenas porções da Bolívia e Paraguai. A compreensão desse sistema é muito importante, já que para preservar é necessário conhecer. Assim, através da utilização de imagens MODIS, objetivou-se estimar as diferenças de cobertura do solo do Pantanal entre os anos de 2003 e 2010, avaliando a capacidade dessas imagens na identificação das mudanças na cobertura do solo da região. O limite de Pantanal adotado foi adaptado de limites consagrados na literatura; o método utilizado para a classificação das imagens foi o da classificação automática não supervisionada. Como resultado foi identificada a diminuição da vegetação arbóreo-arbustiva e o aumento das áreas de gramíneas entre os anos de estudo.
\end{abstract}

Palavras-chave: geotecnologias; análise multitemporal; MODIS; Pantanal.

\begin{abstract}
The Pantanal is one of the richest Brazilian ecosystems in terms of biodiversity, extending into the territories of Mato Grosso and Mato Grosso do Sul, as well as small portions of Bolivia and Paraguay. Understanding this system is very important because in order to preserve it is necessary to understand. Thus, using MODIS images, the present work aimed to estimate the differences in soil covering the Pantanal region between the years 2003 and 2010, evaluating the capacity of these images to identify changes in land cover. The Pantanal boundary used was adapted from boundary consecrated in the literature. The method used for image classification was the unsupervised automatic classification. As a result we identified a decrease in forest vegetation and an increase in grassland areas during the studied years.
\end{abstract}

Keywords: geotechnology; multitemporal analysis; MODIS; Pantanal.

\section{INTRODUÇÃO}

O Pantanal, patrimônio da humanidade e importante área úmida mundial, corresponde a uma extensa planície sedimentar com cotas altimétricas entre 80 e $150 \mathrm{~m}$. A região é sujeita a inundações sazonais decorrentes do acúmulo de águas pluviais provenientes do planalto adjacente. Segundo o regime de inundações, é o fator ecológico fundamental do Pantanal e determina os pulsos dos principais processos bióticos e abióticos, bem como as composições específicas das unidades de paisagem (ADÁMOLI, 1986, 1995).

A compreensão desse sistema é importante para a manutenção de seu equilíbrio, pois a dinâmica regional de escoamento das águas é delicada e tem relação com o transporte de sedimentos, erosão e carreamento de nutrientes ao solo, assim como a manutenção das pastagens nativas e da pecuária, principal atividade econômica regional (ALVARENGA et al., 1984).

'Doutor em Geologia Ambiental pela Universidade Federal do Paraná (UFPR) - Curitiba (PR), Brasil. Professor na Universidade Federal de Mato Grosso do Sul (UFMS) - Campo Grande (MS), Brasil.

²Engenheira Ambiental pela UFMS - Campo Grande (MS), Brasil.

3Doutor em Ciências pela Universidade Federal de São Carlos (UFSCAR) - São Carlos (SP), Brasil. Professor da Universidade Ananguera-Uniderp - Campo Grande (MS), Brasil. ${ }^{4}$ Doutora em Biologia Vegetal pela Universidade Estadual Paulista Júlio de Mesquita Filho (UNESP) - Rio Claro (SP), Brasil. Professora na UFMS - Campo Grande (MS), Brasil. ${ }_{5}^{5}$ Mestre em Saneamento Ambiental e Recursos Hídricos pela UFMS - Campo Grande (MS), Brasil. Professora voluntária na UFMS - Campo Grande (MS), Brasil. Endereço para correspondência: Camila Mioto - Universidade Federal de Mato Grosso do Sul, bloco 7 - Laboratório de Geoprocessamento para Aplicações Ambientais Cidade Universitária, s/n - 78720-100 - Campo Grande (MS), Brasil - E-mail: ea.mioto@gmail.com

Recebido: 27/03/12 - Aceito: 15/04/14 - Reg. ABES: 305 
Mudanças na cobertura do solo representam uma ameaça à sustentabilidade desse e de outros ecossistemas, particularmente quando há conversão de formas de vegetação nativa em áreas antrópicas. Tais conversões ocasionam a aceleração dos processos de mudança naturais, fragmentação da paisagem, perda de biodiversidade, poluição das águas, desequilíbrio no ciclo do carbono, alteração do microclima, erosão e degradação do solo, entre outros (PIMENTEL et al., 1995; LAL \& BRUCE, 1999; KLINK \& MACHADO, 2005; CARVALHO et al., 2009).

Conceitua-se dinâmica da cobertura do solo como as mudanças nos seus padrões decorrentes das atividades antrópicas através do tempo (PARANHOS FILHO et al., 2008). Há uma variedade de fatores que influenciam essas mudanças, como, por exemplo, as políticas governamentais de expansão das fronteiras agrícolas ou o crescimento populacional.

O mapeamento da cobertura do solo através dos anos é uma importante ferramenta de gestão e planejamento ambiental. Por sua vez, o sensoriamento remoto, aliado às demais geotecnologias, é certamente a alternativa mais apropriada para se estudar essa dinâmica. Sensores como o MODIS (Moderate Resolution Imaging Spectroradiometer), embarcado nos satélites TERRA e AQUA, são capazes de imagear extensas áreas em um curto período de tempo, oferecendo assim uma excelente ferramenta de análise ambiental.

Abdon et al. (2007) já ressaltavam que o conhecimento do Pantanal, através da identificação e mapeamento do seu uso do solo, relacionado aos diferentes tipos de vegetação originais, bem como seu estado de preservação, são fatores importantes para a formulação de políticas públicas que objetivem a conservação e o uso sustentável da biodiversidade nos diferentes níveis administrativos, federal, estadual e municipal.

Nesse sentido, é de fundamental importância definir o limite da área de estudo, no caso, o Pantanal. Entretanto, para essa região não há uma base delimitada fisicamente, já que seu contorno não é claro (SILVA \& ABDON, 1998). Além disso, existe a problemática na identificação de suas sub-regiões, já que, apesar de ser caracterizado pelo processo de alagamento, alguns detalhes conferem características distintas a cada subunidade, subdividindo o Pantanal em diversos "Pantanais" (MIOTO et al., 2012).

Entretanto, discordâncias aparecem quando se fala dos limites de cada área, visto que cada autor utilizou em sua delimitação critérios específicos e o material disponível para tal. Desse modo, podem ser encontradas na literatura diversas delimitações do Pantanal, as quais variam em área e em número de sub-regiões (MIOTO et al., 2012).
Nesse contexto, este trabalho tem por objetivo estimar as mudanças na cobertura do solo do Pantanal entre 2003 e 2010, além de contribuir para a delimitação do Pantanal através da utilização de ferramentas de sensoriamento remoto, em especial as imagens MODIS, avaliando, assim, a capacidade dessas imagens de grande amplitude, que são gratuitas.

\section{METODOLOGIA}

\section{Área de estudo}

O Pantanal está localizado no centro da América do Sul e além do Brasil, ocupa porções da Bolívia e Paraguai (Figura 1). Na parte brasileira, encontra-se inserido na região Centro-Oeste, no interior da Bacia do Alto Paraguai (BAP), ocupando cerca de $48.000 \mathrm{~km}^{2}$ no Estado de Mato Grosso (MT) e $89.000 \mathrm{~km}^{2}$ no Mato Grosso do Sul (MS). Essa grande área úmida ocupa áreas parciais de 16 municípios, sendo sete municípios no MT (Barão de Melgaço, Cáceres, Itiquira, Lambari D’Oeste, Nossa Senhora do Livramento, Poconé e Santo Antônio do Leverger) e nove no MS (Aquidauana, Bodoquena, Corumbá, Coxim, Ladário, Miranda, Sonora, Porto Murtinho e Rio Verde de Mato Grosso) (ABDON et al., 2006).

No Pantanal, a distribuição da chuva é marcadamente sazonal. Entre os meses de outubro e março ocorre a intensificação das chuvas, caracterizando o período da cheia. De maio a setembro a incidência de chuva diminui, determinando o período da seca. Na planície sem sempre existe uma relação direta entre a precipitação-vazão. A vazão nesses rios é maior a montante do que a jusante. Assim, é frequente o transbordamento das águas do leito principal para o leito menor e a retenção desse volume de água nas depressões da planície. A baixa capacidade de transporte dos rios e o consequente acúmulo de sedimentos elevam o nível dos rios e eles deixam de ser a principal drenagem da bacia e funcionam como um divisor, recebendo a vazão dos rios do planalto e alimentando a planície (OLIVEIRA et al., 2012).

\section{Pré-processamento dos dados e delimitação das sub-regiões}

Para a realização deste estudo foram utilizadas imagens do sensor MODIS, o qual se encontra a bordo dos satélites TERRA e AQUA e apresenta inúmeras vantagens, como o fato de suas imagens já serem corrigidas geograficamente e radiometricamente, minimizando a influência de nuvens e aerossóis, que muitas vezes interferem na utilização dos produtos orbitais. Soma-se a isso o fato dessas imagens apresentarem resoluções espaciais de 250, 500 e 
$1000 \mathrm{~m}$, imageando grandes extensões territoriais, e estarem disponíveis de forma gratuita na rede.

Assim, foram utilizadas imagens MODIS com resolução espacial de $500 \mathrm{~m}$, do período de seca, entre 14 e 21 de setembro dos anos de 2003 e 2010 (NASA, 2003, 2010). É interessante destacar que, apesar de apresentar baixa resolução espacial, é possível identificar os alvos como vegetação, solo e água com clareza. Outro fator que contribuiu para a escolha dessas imagens é que para abranger a totalidade da área de estudo são necessárias apenas duas cenas de mesma data, fato que elimina as variações sazonais e fenológicas presentes em outros sensores, melhorando o produto obtido. Esses produtos provêm as bandas 1 a 7 , formato hdf e projeção sinusoidal. Cada pixel contém a melhor observação de refletância no período de oito dias, ou seja, aqueles observados quando há ausência de nuvens, sombras de nuvens e aerossóis.

Assim, após a aquisição das imagens pelo site da Agência Espacial Norte-Americana (NASA), as duas cenas que compõem a região foram mosaicadas, reprojetadas para UTM, Zona 21 (Datum WGS 84) e convertidas para o formato geotiff através da ferramenta MODIS Reprojection Tool (MRT (MODIS Reprojection Tool).

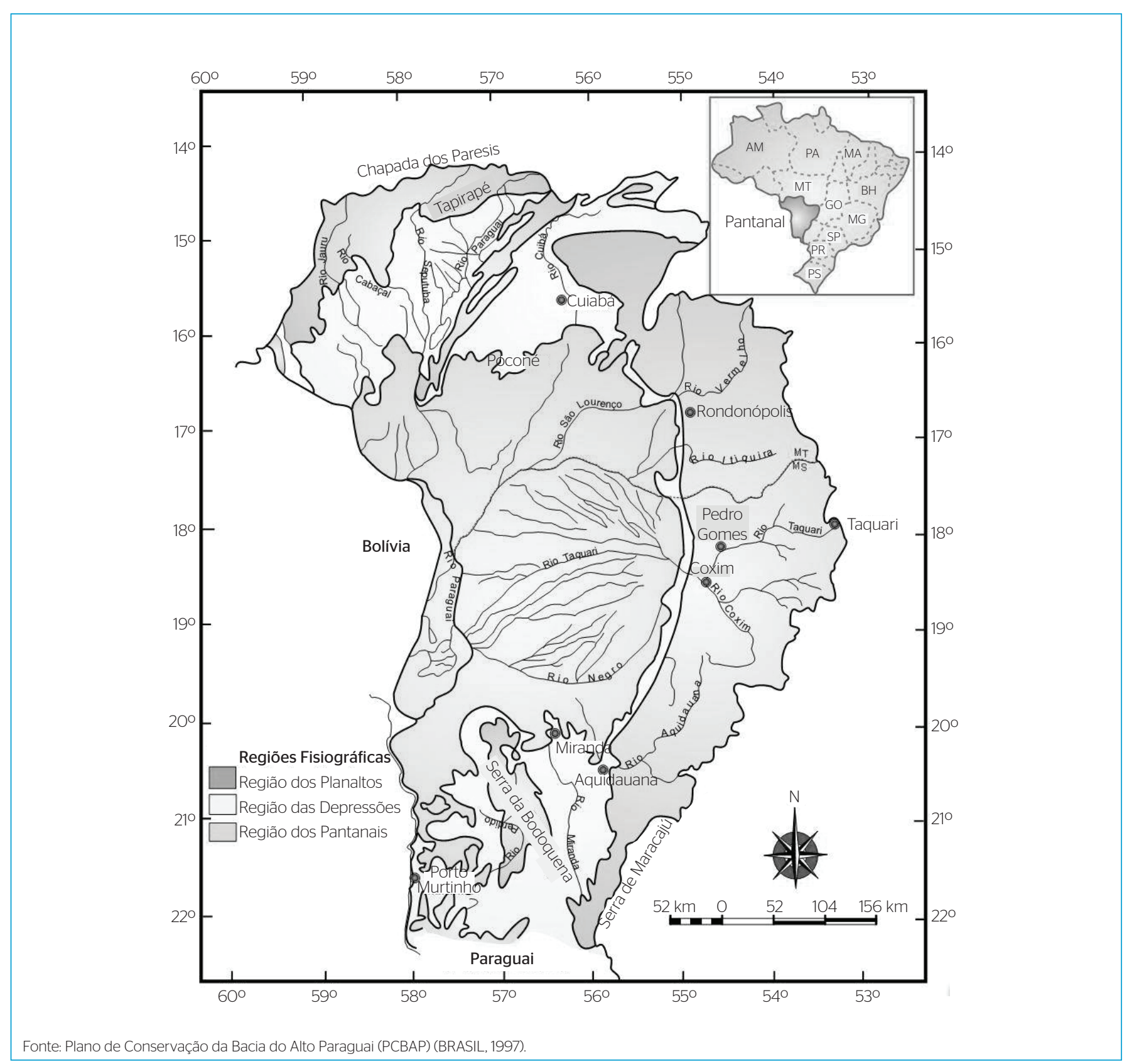

Figura 1 - Regiões Fisiográficas do Pantanal. 
Para auxiliar na identificação das sub-regiões do Pantanal, foi utilizada a composição falsa-cor e o índice de vegetação por diferença normalizada (NDVI), sendo esse o resultado de uma operação matemática entre as bandas do vermelho e do infravermelho próximo (Equação 1).

$N D V I=\frac{R_{2}-R_{1}}{R_{2}-R_{1}}$

Sendo:

$\mathrm{R}_{1}$ : banda do vermelho

$\mathrm{R}_{2}$ : banda do infravermelho próximo (ROUSE et al., 1974).

Assim, observando as diferenças de textura e padrão, vegetação, inundação e solo foram traçados os limites de cada uma das sub-regiões do Pantanal, tomando-se como base os limites propostos por Adámoli (1982) e Silva e Abdon (1998).

\section{Cobertura do solo para os anos de 2003 e 2010}

O método utilizado para a identificação das classes de cobertura do solo foi a classificação automática não supervisionada, a qual se baseia no princípio de que o sistema é capaz de identificar por si só as diferentes classes que compõem a imagem (CRÓSTA, 1993). Nesse tipo de classificação não há a necessidade de um trabalho inicial de treinamento do sistema, porém, o usuário deverá ser capaz de reconhecer as classes criadas pelo algoritmo de classificação não supervisionada (SCHRADER \& POUNCEY, 1997). Assim, o algoritmo identifica as classes e separa os pixels pertencentes a cada uma delas sem a interferência do usuário. Esse tipo de classificação é muito útil para determinar a composição das classes espectrais dos dados antes de uma análise mais detalhada, que pode ser feita com os métodos de classificação supervisionada (RICHARDS, 1986).

Com o mosaico resultante na etapa de pré-processamento, procedeu-se a classificação automática não supervisionada, com 32 classes. A classificação foi realizada no software Erdas Imagine (ERDAS, 2006).

Devido às limitações tanto espaciais quanto espectrais dos produtos MODIS, que dificultam a separação de classes de cobertura próximas, como cerradão e matas, optou-se por agrupar as classes em três: vegetação de porte arbóreo-arbustivo, áreas úmidas (englobando lagos e rios) e vegetação gramínea (englobando pastagens e áreas cultivadas).

A determinação da mudança da cobertura do solo entre os anos de 2003 e 2010 foi realizada pela combinação das classificações resultantes em formato raster. Os mapas resultantes da cobertura do solo para 2003 e 2010, assim como o de mudança de cobertura, foram obtidos pela conversão das classificações em formato matricial para o vetorial. A menor unidade de cobertura adotada foi de 50 hectares.

Com o intuito de verificar qual a sub-região do Pantanal que apresentou a maior mudança de cobertura de solo nos anos observados, foi realizado o recorte da classificação através dos limites de Pantanais encontrados.

\section{RESULTADOS E DISCUSSÃO}

Através da fotointerpretação das imagens MODIS, na composição falsa-cor e NDVI, foi possível delimitar e quantificar o Pantanal em $152.389 \mathrm{~km}^{2}$, obtendo-se o limite de 10 distintas sub-regiões (Figura 2). Apesar do limite aqui utilizado ser baseado nos trabalhos de Adámoli (1982) e Silva \& Abdon (1998), devido a diferenças de

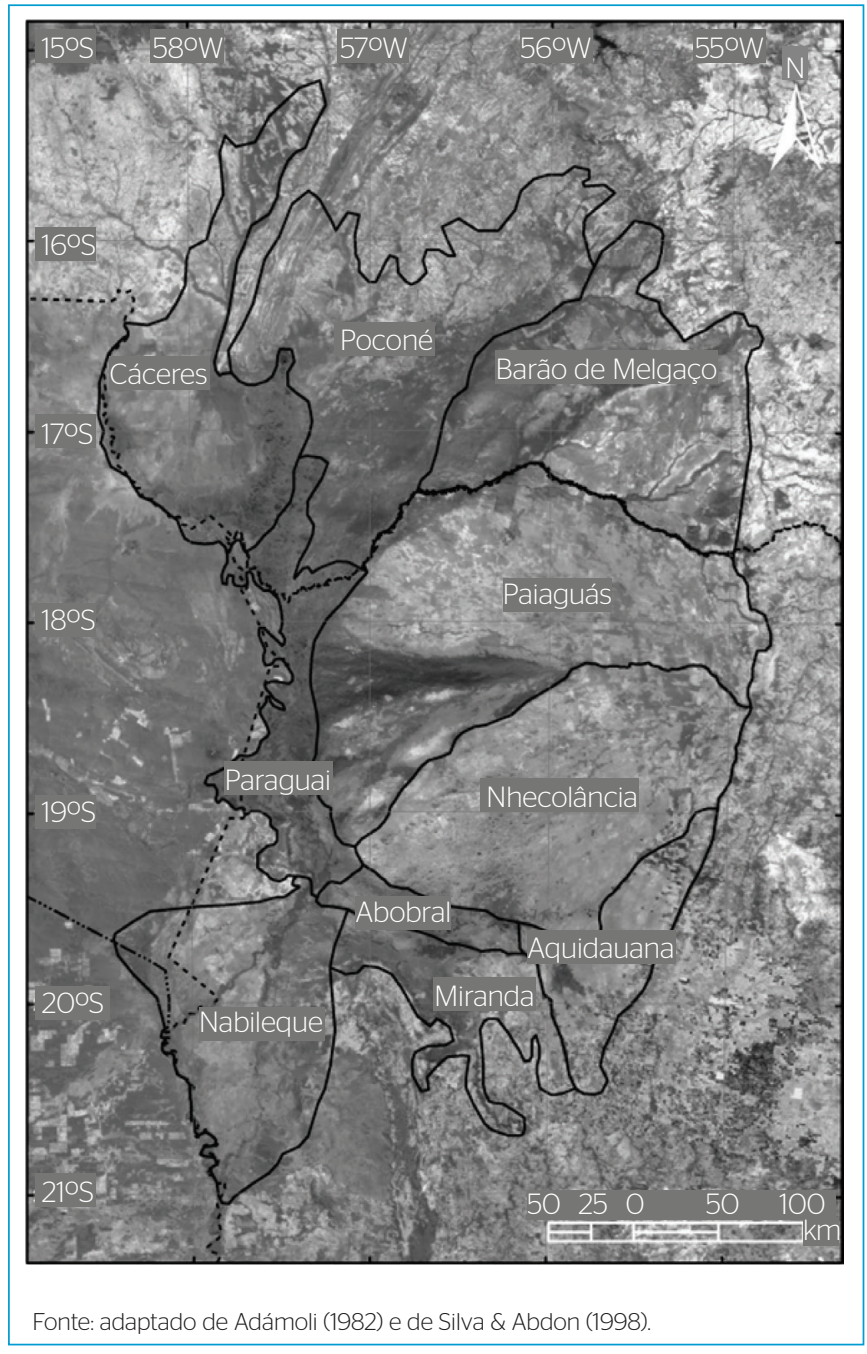

Figura 2 - Imagem MODIS da região do Pantanal com os limites das suas diferentes sub-regiões. O limite tracejado corresponde ao limite do Brasil. 
Tabela 1 - Participação, em área, das regiões da planície pantaneira.

\begin{tabular}{l|c|c} 
Nome & Área $\left(\mathrm{km}^{2}\right)$ & Porcentagem (\%) \\
Abobral & 2.566 & 1,7 \\
\hline Aquidauana & 6.748 & 4,4 \\
\hline Barão de Melgaço & 20.466 & 13,4 \\
\hline Cáceres & 15.864 & 10,4 \\
\hline Miranda & 7.023 & 4,6 \\
\hline Nabileque & 15.021 & 9,9 \\
\hline Nhecolândia & 22.419 & 14,7 \\
\hline Paiaguás & 30.542 & 20 \\
\hline Paraguai & 8.905 & 5,8 \\
\hline Poconé & 22.833 & 15 \\
\hline Pantanal & 152.387 & 100 \\
\hline
\end{tabular}

critérios e métodos utilizados na delimitação, os contornos cartográficos tornaram-se diferentes. Assim, os valores de área, tanto para o limite externo como para os internos, também apresentaram modificações. As diferentes regiões encontradas e seu respectivo valor de área estão dispostos na Tabela 1.

A Figura 3 demonstra os resultados das classificações automáticas não supervisionadas das imagens MODIS dos anos 2003, à esquerda, e 2010, à direita.

A Figura 4 indica a porcentagem de cada classe de cobertura do solo obtidas nas imagens de 2003, à esquerda, e de 2010, à direita.

Em 2003, o percentual de área de gramínea era de 36\%. Já em 2010, houve um aumento das áreas desse tipo de cobertura, passando a representar $50 \%$ da região pantaneira. Em relação à porcentagem de área úmida entre os anos de 2003 e 2010, percebeu-se que também houve um aumento, passando de 5 a $8 \%$.
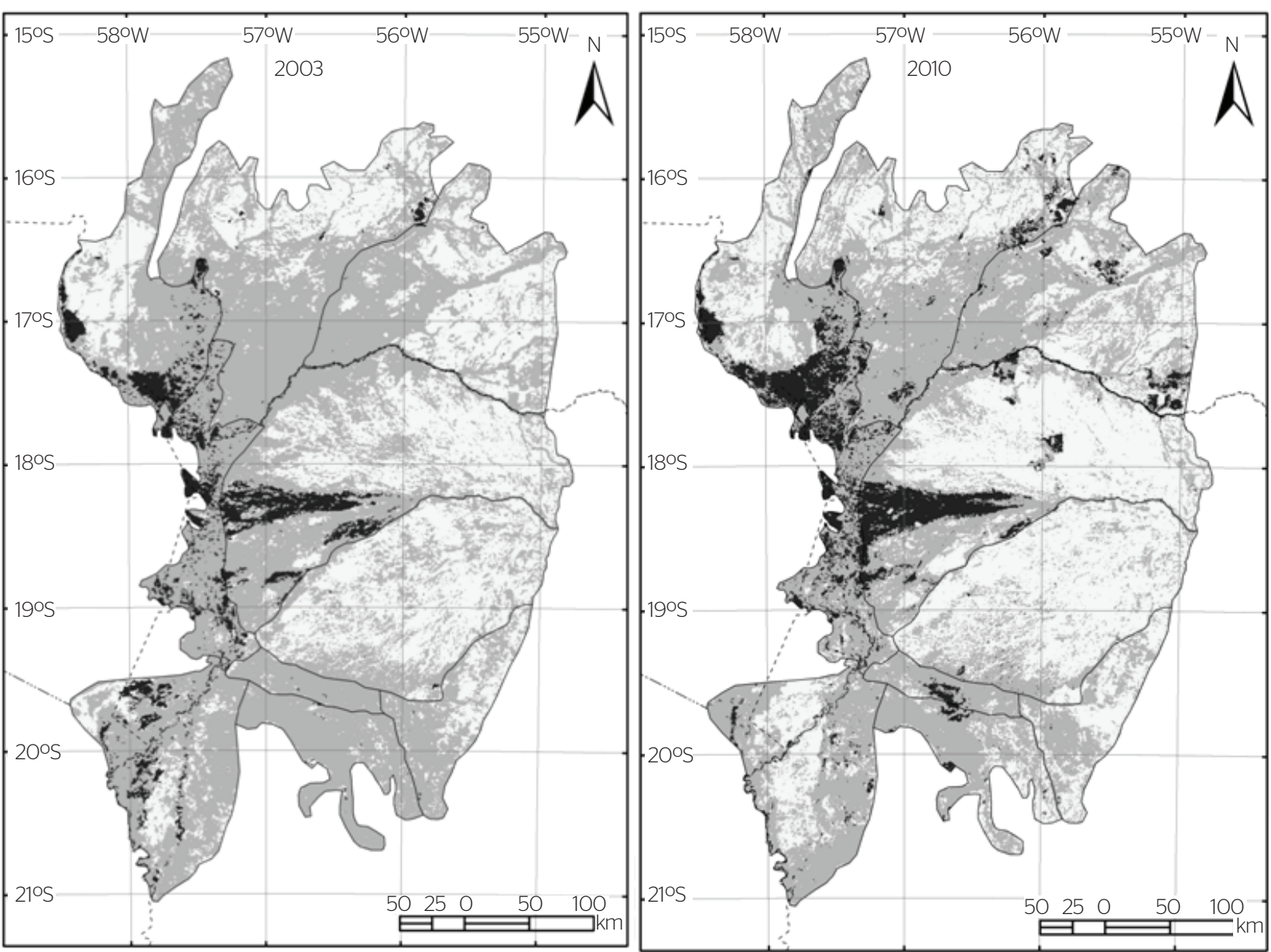

Úmido $\square$ Gramínea $\square$ Arbustiva e Arbórea

Figura 3 - Cobertura do solo em 2003 e 2010. 
A classe arbóreo-arbustiva representava em 2003, 59\% de todo o Pantanal. Em 2010, essa percentagem foi para 42\%, indicando que houve processo de retirada de vegetação arbóreo-arbustiva, dando lugar à classe gramínea.

O aumento da classe úmido entre os dois anos indica, com base nos valores numéricos das imagens NDVI, que no ano de 2010 a região recebeu maior quantidade de chuva do que em 2003, pois apresentava mais umidade.

Na Tabela 3 está disposta a quantificação de cada classe de cobertura encontrada em cada sub-região do Pantanal, na imagem de 2003. Na Tabela 4 está disposta a quantificação para o ano de 2010.

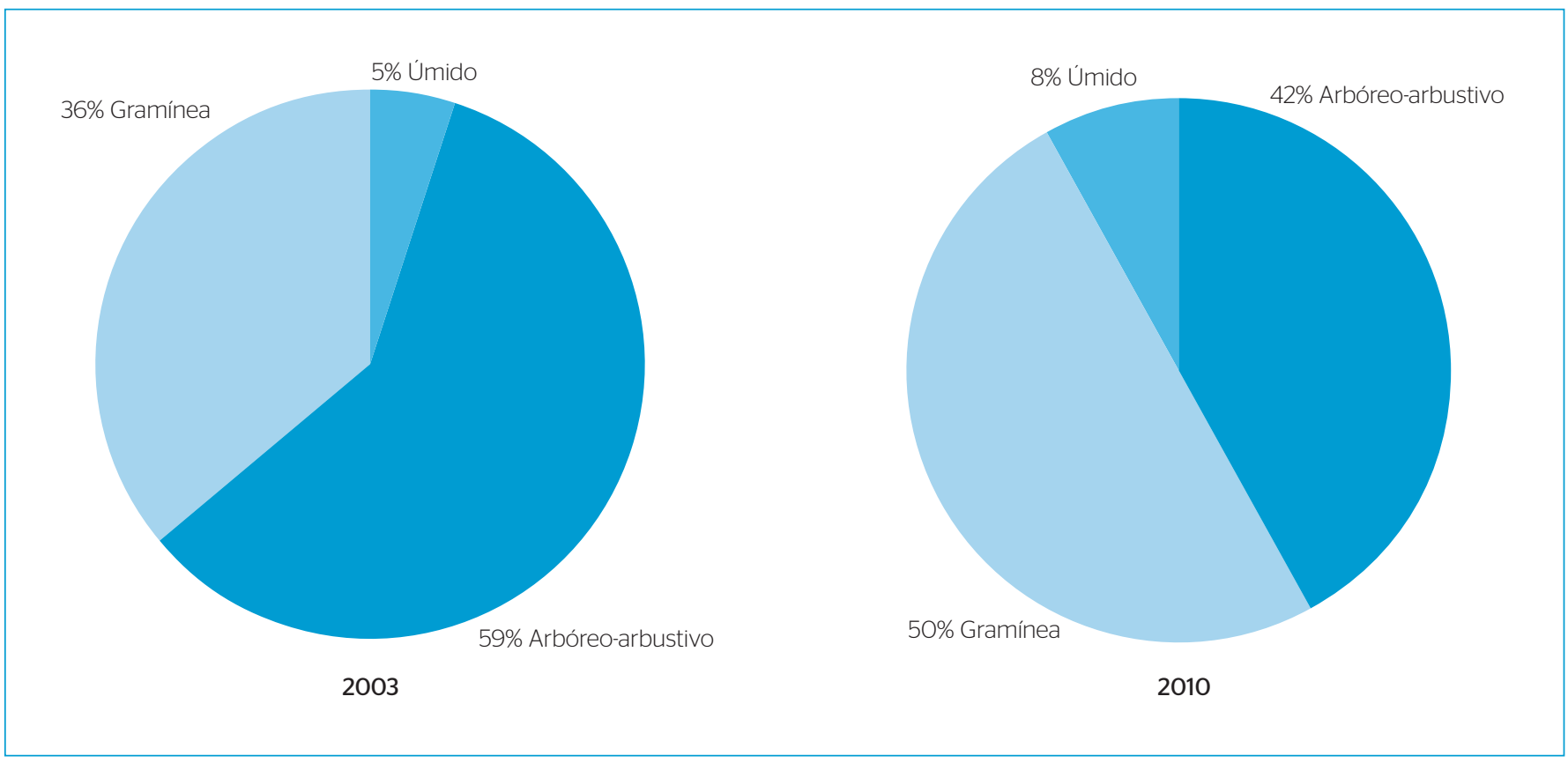

Figura 4 - Gráficos das quantificações da cobertura de solo da imagem MODIS dos anos de 2003 e 2010.

Tabela 3- Quantificações da assinatura espectral em relação à cobertura de solo do Pantanal, na imagem de 2003.

\begin{tabular}{l|c|c|c}
\multirow{2}{*}{ Pantanal } & \multicolumn{3}{|c}{ Classes (\%) } \\
\cline { 2 - 4 } & Úmido & Gramínea & Arbóreo-arbustiva \\
\hline Abobral & 0,37 & 3,85 & 95,78 \\
\hline Aquidauana & 0,15 & 32 & 68,25 \\
\hline Barão de Melgaço & 0,18 & 44,56 & 55,26 \\
\hline Cáceres & 10,58 & 30 & 59,43 \\
\hline Miranda & 0,42 & 5,07 & 94,51 \\
\hline Nabileque & 8,96 & 19 & 71,76 \\
\hline Nhecolândia & 0,12 & 62,28 & 37,60 \\
\hline Paiaguás & 8,22 & 41 & 50,46 \\
\hline Paraguai & 21,94 & 2,35 & 75,71 \\
\hline Poconé & 0,90 & 35 & 63,66 \\
\hline
\end{tabular}

Tabela 4 - Quantificações da assinatura espectral em relação à cobertura de solo do Pantanal, na imagem de 2010.

\begin{tabular}{l|c|c|c}
\multirow{2}{*}{ Pantanal } & \multicolumn{3}{|c}{ Classes (\%) } \\
\cline { 2 - 4 } Abobral & Úmido & Gramínea & Arbóreo-arbustiva \\
\hline Aquidauana & 8,78 & 8,58 & 82,64 \\
\hline Barão de Melgaço & 3,18 & 48,76 & 51,05 \\
\hline Cáceres & 18,82 & 37,80 & 58,28 \\
\hline Miranda & 3,00 & 22,91 & 47,51 \\
\hline Nabileque & 3,73 & 30,04 & 64,08 \\
\hline Nhecolândia & 0,38 & 74,03 & 25,59 \\
\hline Paiaguás & 11,73 & 55,12 & 33,15 \\
\hline Paraguai & 29,14 & 3,24 & 67,62 \\
\hline Poconé & 3,72 & 36,35 & 59,94 \\
\hline
\end{tabular}


Os processos de mudança de cobertura do solo mais intensos são verificados nos pantanais que apresentam maior facilidade de acesso, como no caso de Aquidauana e Miranda, em MS. Nessas áreas, a ocupação está transformando as formações florestais, como as cordilheiras e capões, em pastagens, como a braquiária. Os pantanais da Nhecolândia, Paiaguás e Abobral também podem ser enquadrados nessa situação.

O Pantanal que apresentou menor variação de cobertura de solo foi o Poconé, onde a classe arbustivo-arbórea diminuiu somente $3,72 \%$ entre 2003 e 2010. O único Pantanal que não sofreu a diminuição da classe arbóreo-arbustiva foi o Pantanal de Barão do Melgaço, já que a porcentagem dessa classe passou de 55 para $58 \%$.

\section{CONCLUSÃO}

A fotointerpretação das imagens MODIS permitiu delimitar o Pantanal em 10 diferentes sub-regiões num total de $152.389 \mathrm{~km}^{2}$, valor que difere das demais delimitações encontradas na literatura devido à metodologia e aos critérios utilizados neste trabalho.

Através da classificação automática não supervisionada das imagens do satélite TERRA/AQUA, sensor MODIS, entre os anos de 2003 e 2010, foi possível realizar a análise multitemporal da cobertura do solo do Pantanal, demonstrando as mudanças ocorridas na cobertura do solo da região.

Foi possível identificar que houve uma diminuição das áreas de vegetação arbóreo-arbustiva, com o consequente aumento das áreas de gramíneas. Isso indica que o Pantanal está sofrendo processo de desmatamento, no qual as regiões de vegetação estão sendo transformadas em regiões de pastagens destinadas à agricultura e pecuária.

Esse fato é muito preocupante e, caso não sejam tomadas providências urgentes, a descaracterização da planície pantaneira pode ocorrer bem mais rápido do que é imaginado. Assim, tornam-se necessários o manejo e a conservação adequados dos componentes da biodiversidade do local, com vistas à sobrevivência de espécies e à manutenção de ambientes do domínio Pantanal.

\section{REFERÊNCIAS}

ABDON, M.M. \& SILVA, J.S.V. (2006) Fisionomias da Vegetação nas Subregiões do Pantanal Brasileiro. São José dos Campos: INPE e Embrapa Informática Agropecuária. CR-ROM.

ABDON, M.M.; SILVA, J.S.V.; MARSELHAS e SOUZA, I.; ROMON, V.T:; RAMPAZZO, J.; FERRARI, D.L. (2007) Desmatamento no bioma Pantanal até o ano 2002: relações com a fitofisionomia e limites municipais. Revista Brasileira de Cartografia, v. 59, n. 1, p. 17-24.

ADÁMOLI, J. (1982) O Pantanal e suas relações fitogeográficas com os Cerrados. Discussão sobre o conceito "Complexo do Pantanal". In: $32^{\circ}$ Congresso Nacional de Botânica. Teresina: SBB.

ADÁMOLI, J. (1986) Vegetação e flora. In: Simpósio sobre recursos naturais e socioeconômicos do Pantanal, 1. Anais... Corumbá: Embrapa Pantanal. p. 105-106.

ADÁMOLI, J. (1995) Zoneamento ecológico do Pantanal baseado no regime de inundações. In: Encontro Sobre Sensoriamento Remoto Aplicado a Estudos no Pantanal, 1 Anais... São José dos Campos: INPE. p. 15-17.

ALVARENGA, S.M.; BRASIL, A.E.; PINHEIRO, R.; KUX, H.J.H. (1984) Estudo geomorfológico aplicado à Bacia do Alto Paraguai e Pantanais Mato-grossenses. Boletim Técnico. Série Geomorfológica, 1 . Projeto RADAMBRASIL. Salvador. p. 89-183.

BRASIL (1997). Ministério do Meio Ambiente, dos Recursos Hídricos e da Amazônia Legal. Programa Nacional do Meio Ambiente. Plano de Conservação da Bacia do Alto Paraguai (PCBAP) . v. 2. Brasília: MMA/ SEMAM/PNMA.
CARVALHO, F.M.V.; MARCO JÚNIOR, P.; FERREIRA, L.G. (2009) The Cerrado into-pieces: habitat fragmentation as a function of landscape use in the savannas of central Brazil. Biological Conservation, v. 142, n. 7. p. 1392-1403.

CRÓSTA, A.P. (1993) Processamento Digital de Imagens de Sensoriamento Remoto. UNICAMP/Instituto de Geociências. 164 p.

ERDAS (2006). ERDAS Imagine. Software versão 9.1. Norcross, GA, USA: Leica Geosystems Geospatial Imaging.

KLINK, C.A. \& MACHADO, R.B. (2005) Conservation of the Brazilian Cerrado. Conservation Biology, v. 19, n. 3, p. 707-713.

LAL, R. \& BRUCE, J.P. (1999) The potential of world cropland soils to sequester $\mathrm{C}$ and mitigate the greenhouse effect. Environmental Science \& Policy, v. 2, n. 2, p. 177-185.

MIOTO, C.L.; PARANHOS FILHO, A.C.; ALBREZ, E.A. (2012) Contribuição à caracterização das sub-regiões do Pantanal. Revista Entre-Lugar, v. 3, n. 6, p. 165-180.

NATIONAL AERONAUTICS AND SPACE ADMINISTRATION - NASA (2003, 2010) Imagens de Satélite. TERRA/AQUA - Sensor MODIS. h12v10 e h12v11. Disponível em: <http://modis.gsfc.nasa.gov>. Acesso em: 14 mar. 2011.

OLIVEIRA, A.K.M.; PAGOTTO, T.C.S.; PARANHOS FILHO, A.C:; MOREIRA, É.S. (2012) O desmatamento no Pantanal: causas e consequências. In: ALVES G.L.; MERCANTE M.A.; FAVERO, S. (Org.). Pantanal Sul-Mato-Grossense: ameaças e propostas. 1. ed. Campinas: Autores Associados. v. 1, p. 29-58. 
PARANHOS FILHO, A.C.; LASTORIA, G.; TORRES, T.G. (2OO8) Sensoriamento remoto ambiental aplicado: introdução às geotecnologias. Campo Grande: Ed. UFMS. 198 p.

PIMENTEL, D.; HARVEY, C.; RESOSUDARMO, P.; SINCLAIR, K.; KURZ, D.; MCNAIR, M.; CRIST S.; SHORITZ, L.; FITTON, L.; SAFFOURI, R.; BLAIR, R. (1995) Environmental and economic costs of soil erosion and conservation benefits. Science, v. 267, n. 245201, p. 1117-1123.

ROUSE, J.W.; HASS, R.H.; DEERING, D.W.; SCHELL, J.A. (1974) Monitoring the vernal advancement and retrogradiation (green wave effect) of natural vegetation. Texas, EUA. p. 120. Disponível em: <https://archive. org/details/nasa_techdoc_19740022555>. Acesso em: 17 nov. 2011.

SCHRADER, S. \& POUNCEY, R. (1997) Erdas Field Guide. 4. ed. Atlanta, EUA: Erdas Inc. 656 p.

RICHADS, J.A. (1986) Remote sensing digital image analysis: an introduction. Berlin: Springer-Verlarg. 281 p.

SILVA, J.S.V. \& ABDON, M.M. (1998) Delimitação do Pantanal brasileiro e suas sub-regiões. Pesquisa Agropecuária Brasileira, v. 33, n. especial, p. 1703-1711. 